Supporting Information for

\title{
Thermodynamic Network Cards of Hantzsch Ester, Benzothiazoline and Dihydrophenanthridine Releasing Two Hydrogen Atoms or Ions on 20 Elementary Steps
}

Guang-Bin Shen, ${ }^{*}+$ Yan-Hua Fu ${ }^{\S}$ and Xiao-Qing Zhu, ${ }^{* \dagger}$

SI Potentials of $\mathrm{XH}_{2}, \mathrm{XH}^{-}, \mathrm{X}, \mathrm{XH}^{+}$: Figure $\mathrm{S} 1 \quad \mathrm{~S} 2$

SII Stoichiometric ratio of $\mathrm{XH}_{2}$ reacting with $\mathrm{Y}^{+}$: Figure S2 S3 $\quad$ S3

SIII Measurement of reaction heat: Figure S4 S5

SIV References $\quad$ S5

SV Nuclear magnetic spectrum $\quad$ S6 $\sim \mathrm{S} 8$ 


\section{SI Potentials of $\mathrm{XH}_{2}, \mathrm{XH}^{-}, \mathrm{X}, \mathrm{XH}^{+}$}

Measurements of Redox Potentials. ${ }^{\text {S1 } \sim \text { S4 }}$ Electrochemical experiments, CV and OSWV, were tested at BAS-100B instrument under protection of Ar in dry and deaerated $\mathrm{MeCN}$ at rt (Figure S1). Standard three-electrode was used which consists of $0.1 \mathrm{M} \mathrm{AgNO} / \mathrm{Ag}$ (in $0.1 \mathrm{M} n-\mathrm{Bu}_{4} \mathrm{NPF}_{6} / \mathrm{MeCN}$ ) as reference electrode, Pt wire as assisting electrode and glassy carbon disk as working electrode. $n-\mathrm{Bu}_{4} \mathrm{NPF}_{6}(0.1 \mathrm{M})$ in $\mathrm{MeCN}$ was used as supporting electrolyte.
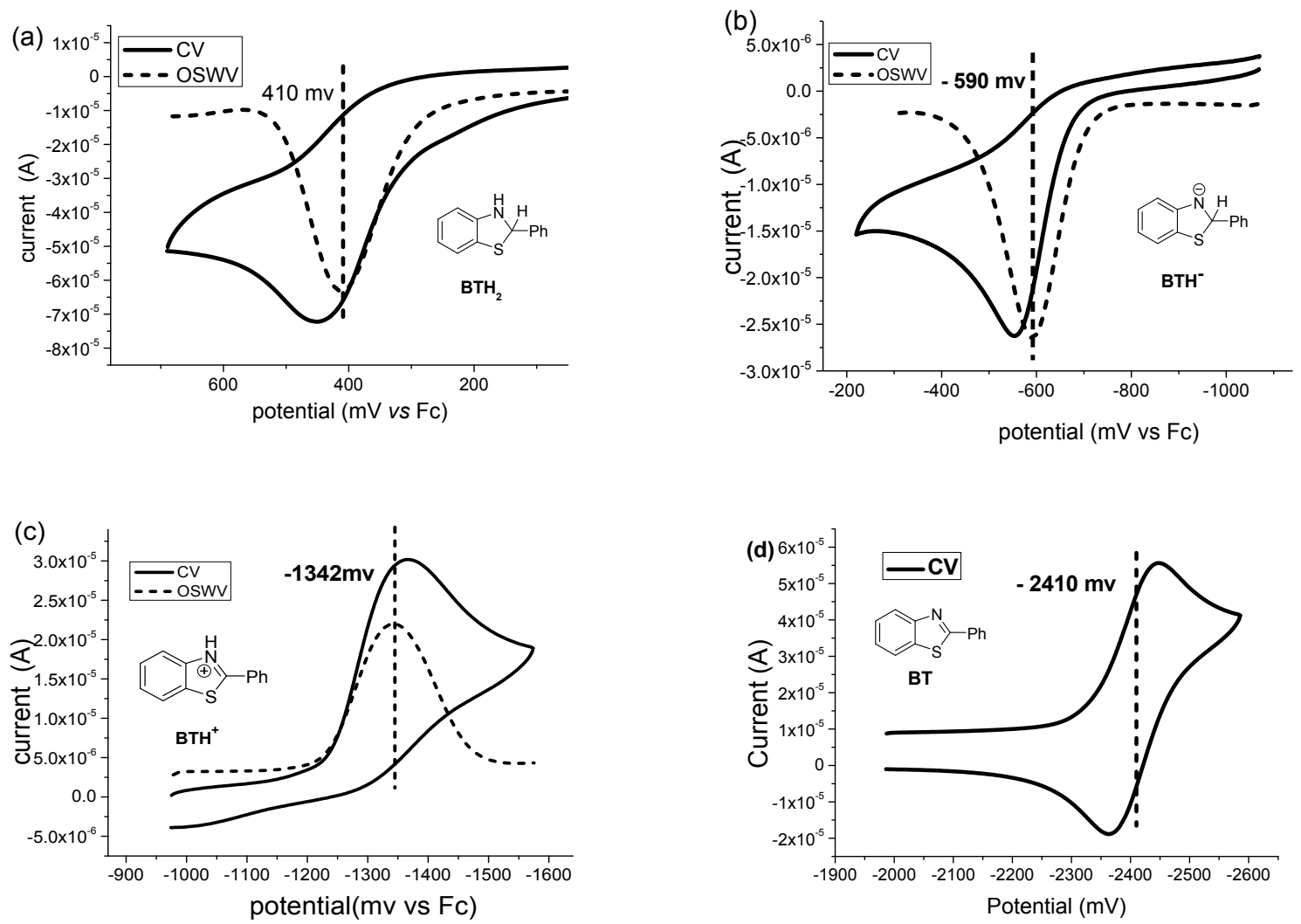

Figure S1. Cyclic voltammetry (CV) and Osteryoung square wave voltammetry (OSWV) in deaerated acetonitrile containing $0.1 \mathrm{Mn}-\mathrm{Bu}_{4} \mathrm{NPF}_{6}$ as supporting electrolyte. (a) The oxidation potential of $\mathrm{BTH}_{2}$. (b) The oxidation potential of $\mathrm{BTH}^{-}$. (c) The reduction potential of $\mathrm{BTH}^{+}$. (d) The reduction potential of BT. 


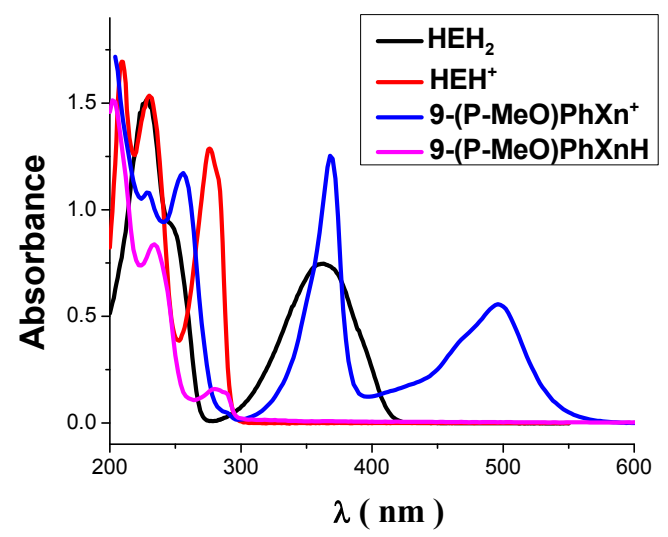

Figure S2. Comparison of absorption spectra of 9-(p-MeO)PhXn ${ }^{+}$, 9-(p-MeO)PhXnH, $\mathrm{HEH}_{2}$ and $\mathrm{HEH}^{+}$in acetonitrile.
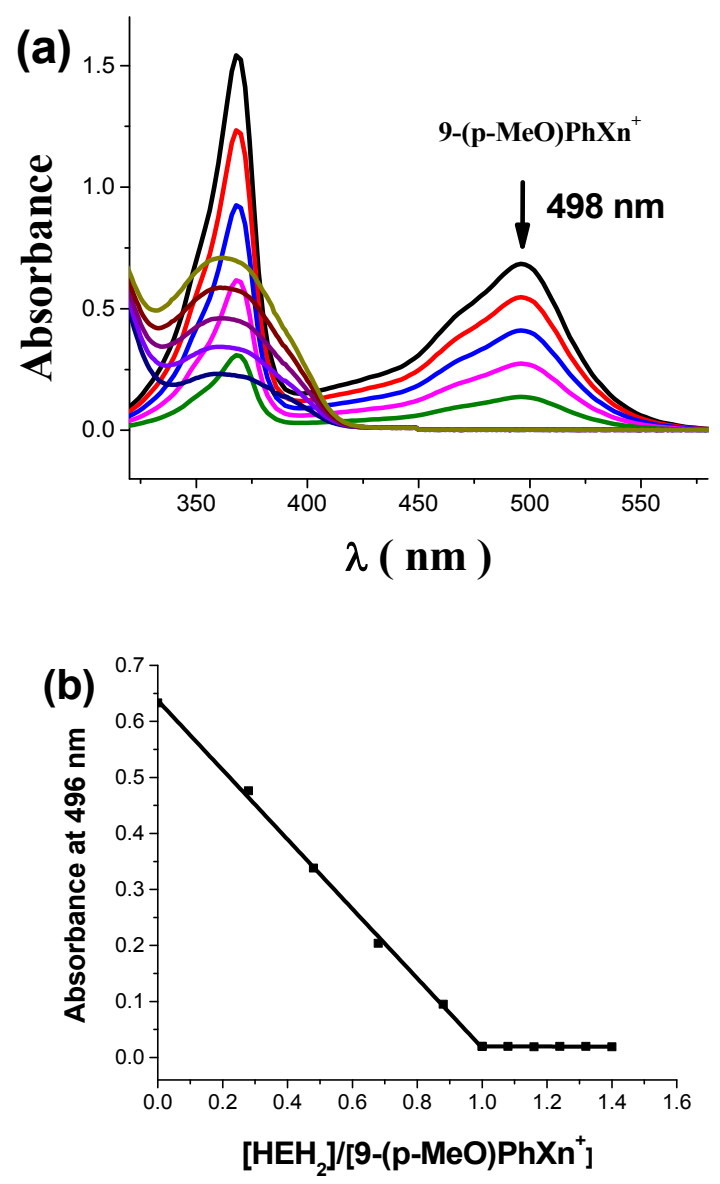

Figure S3. (a) Absorption spectral changes observed for an acetonitrile solution of 9-(p-MeO) $\mathrm{PhXn}^{+}(0.21 \mathrm{mM})$ at various $\mathrm{HEH}_{2}$ concentrations (see arrows in the figure). (b) Plot of the absorbance at $498 \mathrm{~nm}$ vs the molar ratio $\left[\mathrm{HEH}_{2}\right] /\left[9-(\mathrm{p}-\mathrm{MeO}) \mathrm{PhXn}{ }^{+}\right]$. 


\section{SIII Measurement of reaction heat}

Isothermal Titration Calorimetry (ITC). ${ }^{\text {S1 S4 }}$ ITC tests were measured on a CSC4200 calorimeter at $298 \mathrm{~K}$ in MeCN (Figures S4 S5). Calorimeter's action was examined by standard neutralization heat of aqueous $\mathrm{NaOH}$ solution with aqueous $\mathrm{HCl}$ solution $(0.1 \mathrm{M})$. The reaction heat was acquired by integration of every peak with exception of first peak. Data were recorded every 2 seconds.

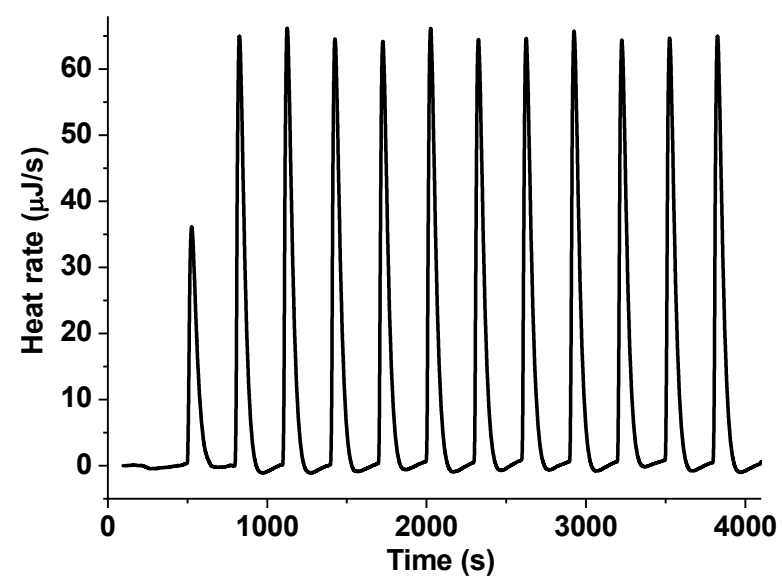

Figure S4. Isothermal titration calorimetry (ITC) for the reaction heat of $\mathrm{HEH}^{-}$with 9-(p-MeO) $\mathrm{PhXn}^{+}$in acetonitrile at $298 \mathrm{~K}$. Titration was conducted by adding $10 \mu \mathrm{L}$ 9-(p-MeO) $\mathrm{PhXn}^{+}$in acetonitrile $(2.07 \mathrm{mM})$ every $400 \mathrm{~s}$ into the acetonitrile containing the $\mathrm{HEH}^{-}$ (ca. $7.0 \mathrm{mM})$.

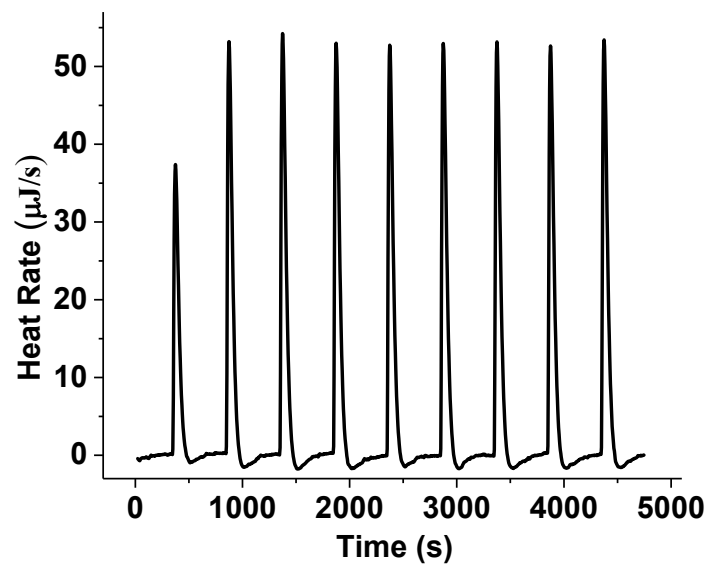

Figure S5. Isothermal titration calorimetry (ITC) for the reaction heat of $\mathrm{HEH}^{-}$with $\mathrm{CF}_{3} \mathrm{SO}_{3} \mathrm{H}$ in acetonitrile at $298 \mathrm{~K}$. Titration was conducted by adding $10 \mu \mathrm{L} \mathrm{HEH}^{-}$in acetonitrile $(2.05 \mathrm{mM})$ every $500 \mathrm{~s}$ into the acetonitrile containing the $\mathrm{CF}_{3} \mathrm{SO}_{3} \mathrm{H}$ (ca. $3.0 \mathrm{mM}$ ). 


\section{SIV References}

(S1) Thermodynamic Parameters of Elementary Steps for 3,5-Disubstituted 1,4-Dihydropyridines To Release Hydride Anions in Acetonitrile. Zhao, H.; Li, Y.; Zhu, X.-Q. ACS Omega 2018, 3, 13598-13608.

(S2) Determination and Comparison of Thermodynamic Driving Forces of Elementary Steps for the Reductions of Alkynes and the Corresponding Alkenes in Acetonitrile. Si, S.-M.; Fu, Y.-H.; Zhu, X.-Q. J. Phys. Chem. C 2015, 119, 62-74.

(S3) (a) A Thermodynamic and Kinetic Study of Hydride Transfer of a Caffeine Derivative. Han, X.; Hao, W.; Zhu, X.-Q.; Parker, V. D. J. Org. Chem. 2012, 77, 6520-6529. (b) Determination of Thermodynamic Affinities of Various Polar Olefins as Hydride, Hydrogen Atom, and Electron Acceptors in Acetonitrile. Cao, Y.; Zhang, S.-C.; Zhang, M.; Shen, G.-B.; Zhu, X.-Q. J. Org. Chem. 2013, 78, 7154-7168.

(S4) Hydride, Hydrogen Atom, Proton, and Electron Transfer Driving Forces of Various Five-Membered Heterocyclic Organic Hydrides and Their Reaction Intermediates in Acetonitrile. Zhu, X.-Q.; Zhang, M.-T.; Yu, A.; Wang, C.-H.; Cheng, J.-P. J. Am. Chem. Soc. 2008, 130, 2501-2516. 
SV Nuclear magnetic spectrum:
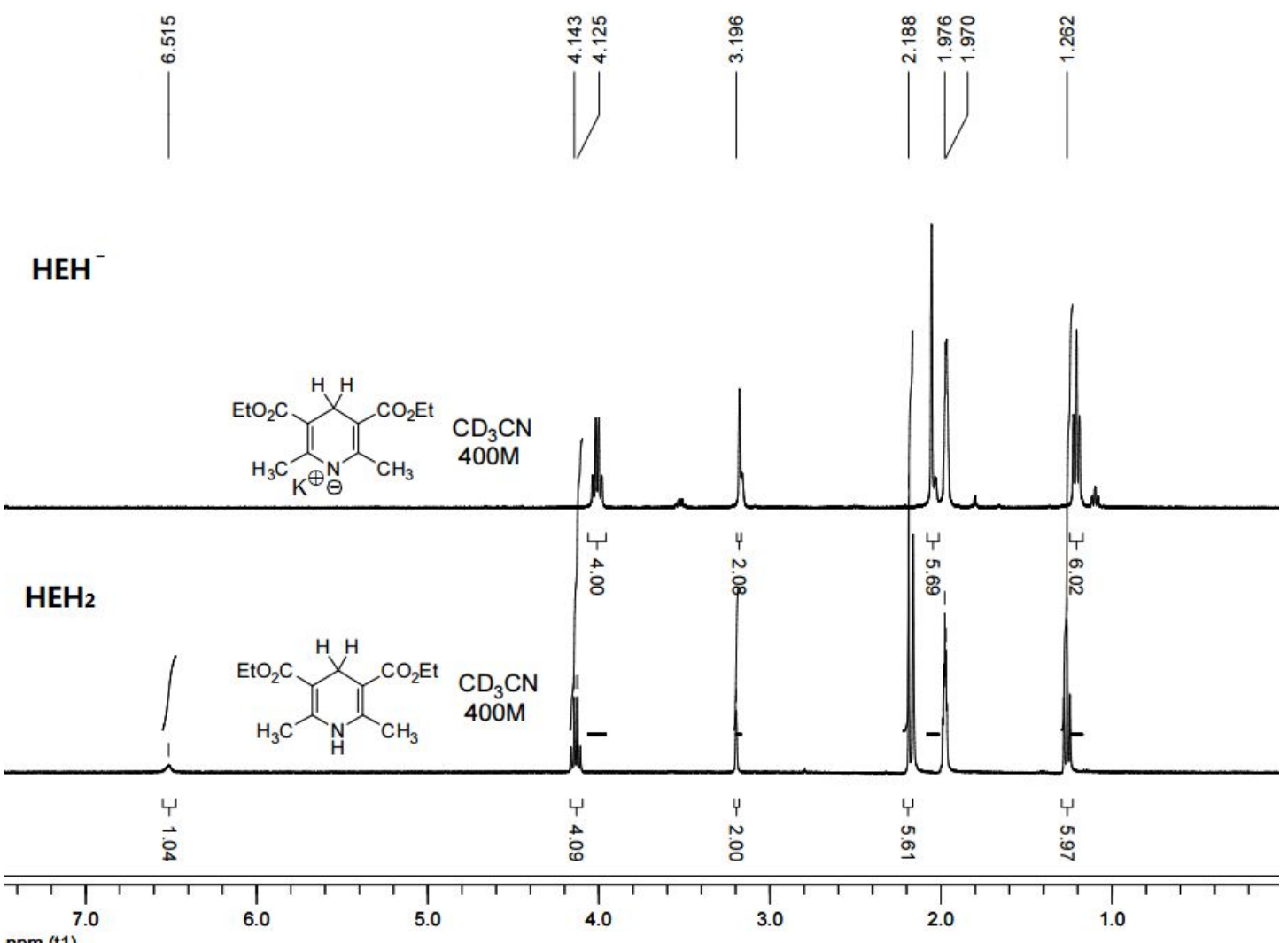

ppm (t1)

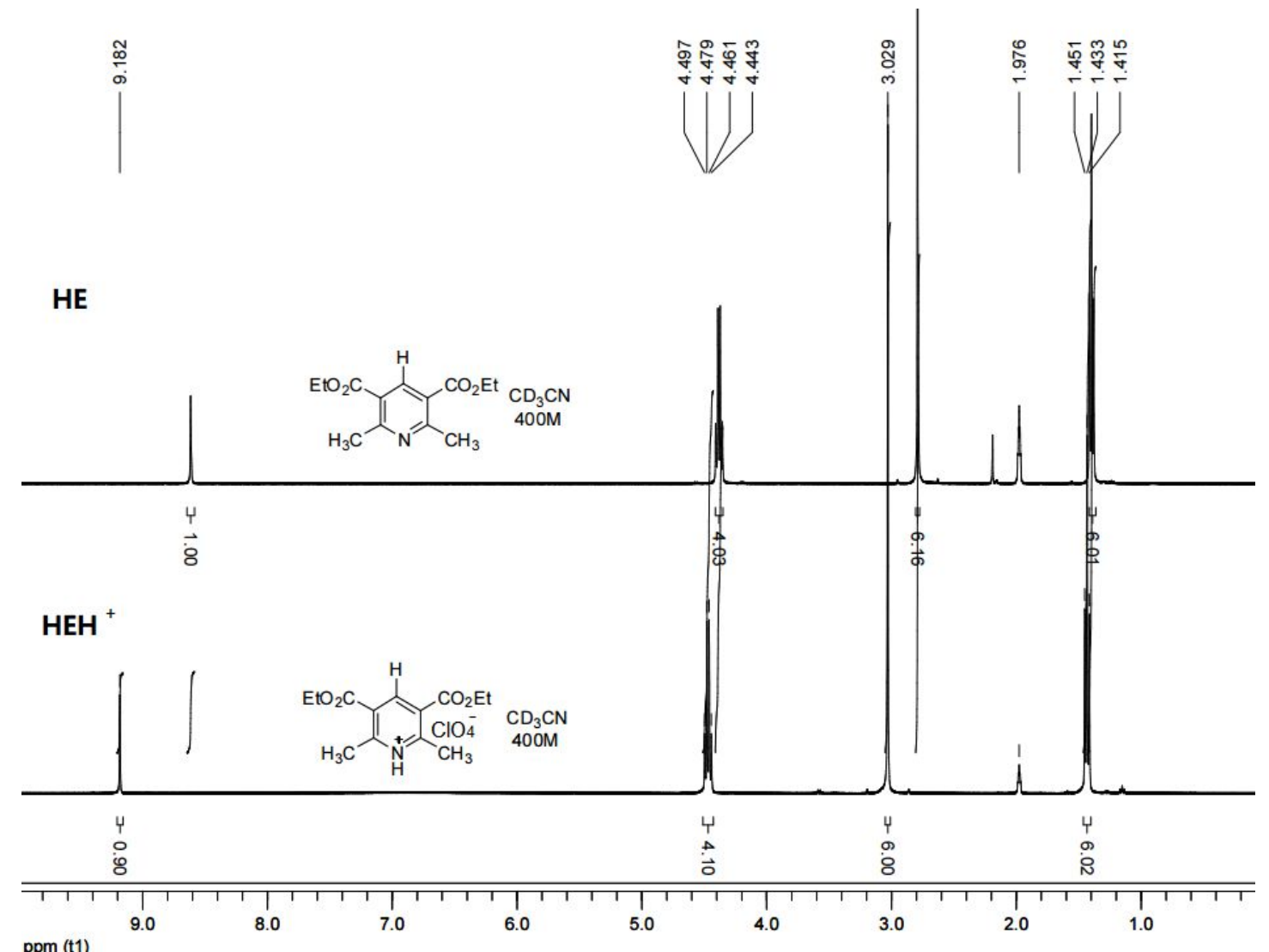

ppm (t1) 


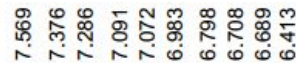

(ivi)

BTH $_{2}$
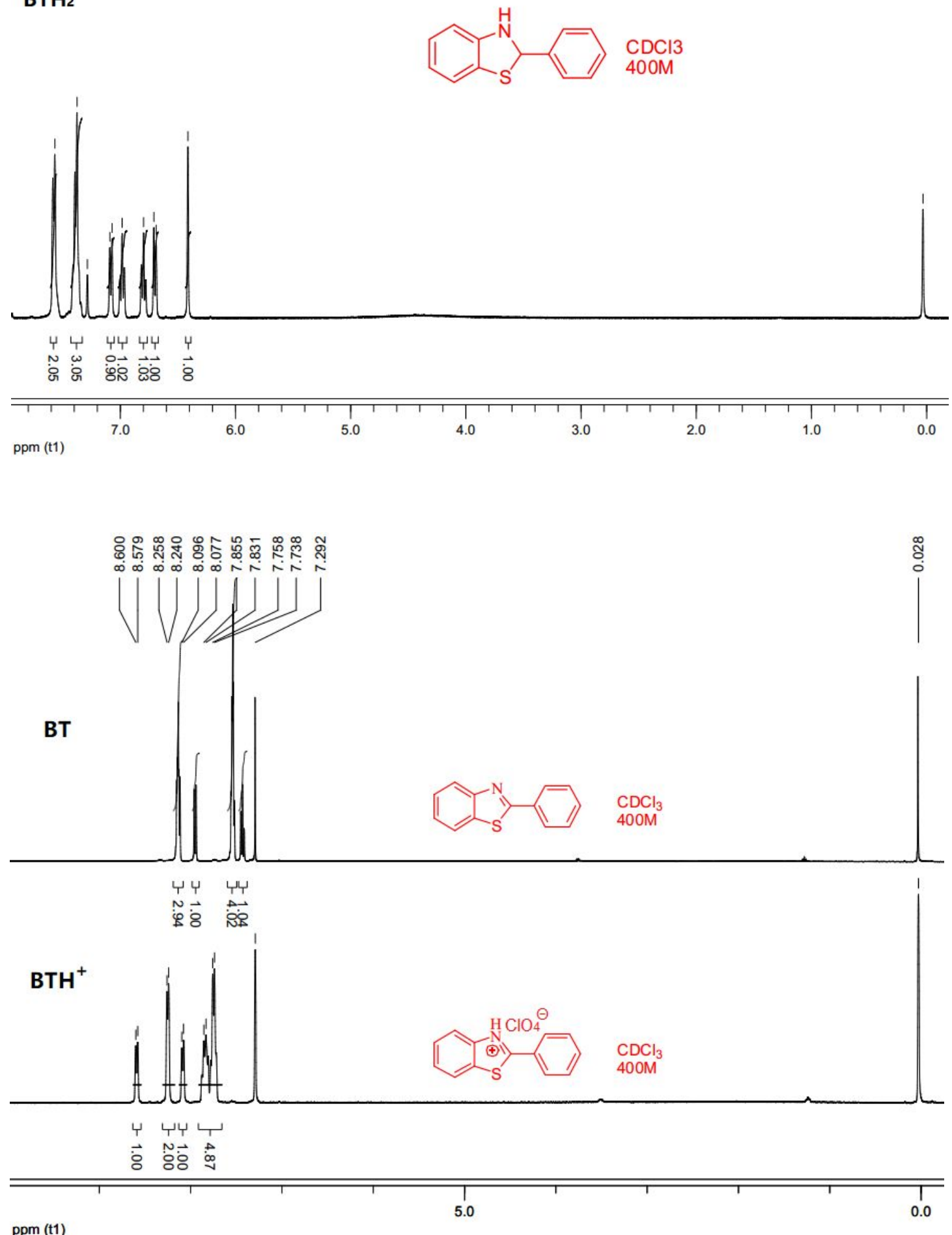

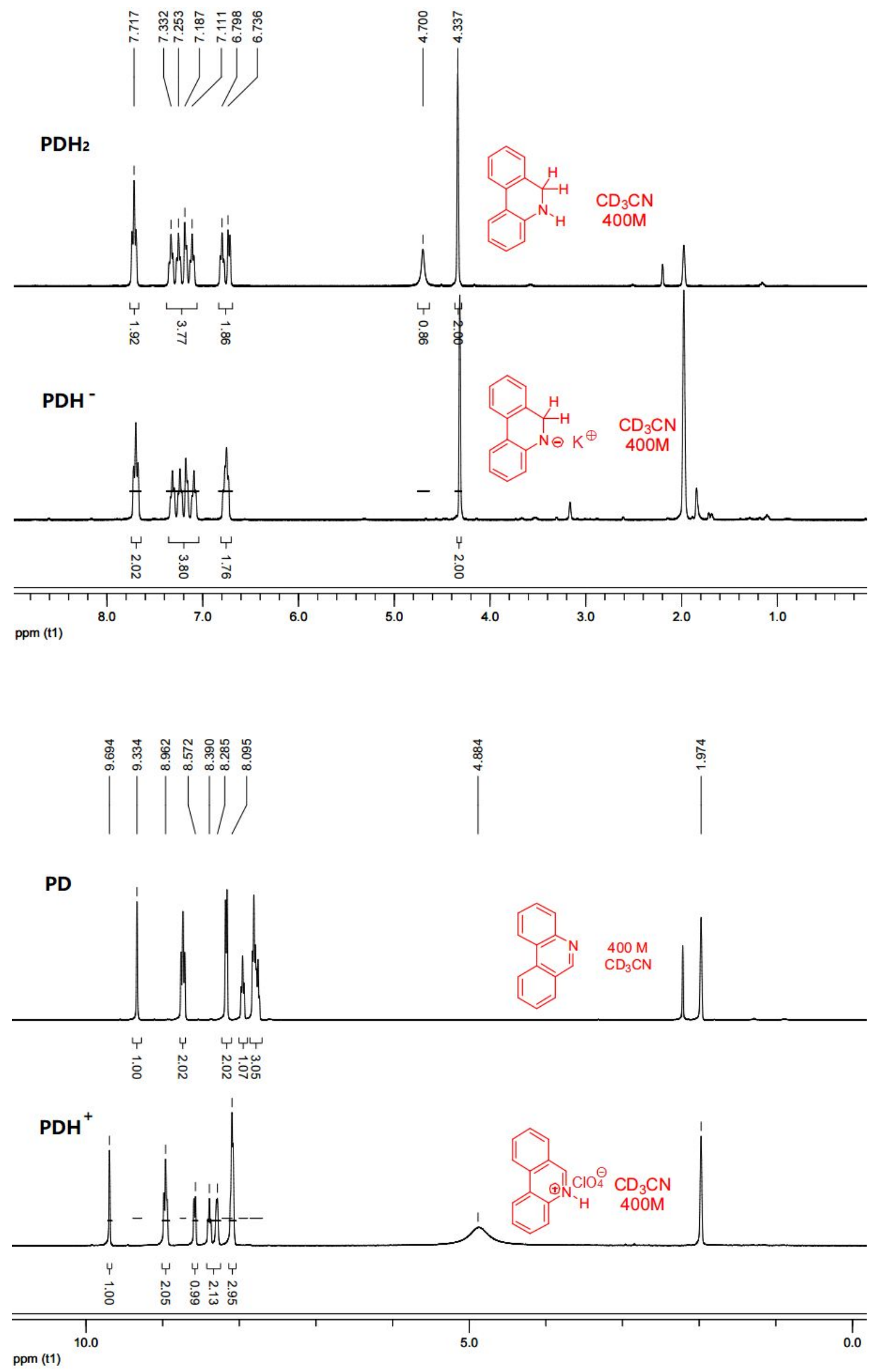